Hardness. 20

Tensile strength. 900 lbs. per sq. in.

Resistance.

0.043 oun pex inch cube

The material can still shrink greatly and improve by a higher heat treatment. This is accomplished in an ordinary porcelain kiln at about $\mathrm{I} 400^{\circ} \mathrm{C}$, the brushes being packed as before, though not in iron, but in fire clay containers or saggers, the whole being covered with coke dust and the cover carefully luted on. The slightest carelessness in this protection process causes a softening of the outer surface of the brush, where a little combustion has removed the binder-carbon. This binder-carbon is still combustible in the presence of an excess of coke powder.

Owing to the severe requirements for railway motor brushes, the work for a long time was devoted exclusively to this field and there is probably still plenty of improvement possible.

As the work has advanced, the refinements of requirements have become more and more apparent, and it is quite evident now that several different carbon brush types are necessary to satisfy the requirements for different types of machines. In case of this particular brush, however, it is worth attention that by slight modifications in the process, such as fineness of grinding, pressure on the hydraulic press, etc., the record of tests kept during the past 2 years shows the following changes:

$\begin{array}{ccc}\text { Hardness. } & \text { Resistance. } & \text { Tensile strength. } \\ 1909 \ldots \ldots .52 .3 & 0.00135 & 1800 \\ 1911 \ldots \ldots \ldots 58-60 & 0.00120 & 2700\end{array}$

Attempts were made to operate without change in the components, as weighed out; all qualities have improved through small refinements.

Development of the railway brush led to trying the same product on other types of electrical apparatus, and it was at once evident that the general brush requirements call for more than one kind of brush and more than a single composition. Generator brushes, while they do not meet the severe conditions met by railway motor brushes and may therefore be softer and of lower physical tests, should have high conductivity and should in use develop a polished commutator without cutting or smutting the metal. A fairly satisfactory type of generator brush may be made almost entirely of ash-free graphite and bindercarbon and will have approximately the following values on test: Hardness, 35 ; resistance, 0.00078 ; tensile strength, 2500; chip test, 6 . It has been found that a brush needs some lubrication qualities which are difficult to express quantitatively. In the past it has even been customary to treat some brushes with oils, vaseline, etc., to give them this lubricating effect. It has also been found possible to improve operation of a commutator by using hard, strong, non-lubricating brushes and to interpose in several of the brushholders a pure graphite brush, which serves to give desired lubrication for the other brushes. This has led to experiments on a combination brush, of which a section is shown (Fig. 6). In this case, by a proper selection of proportions of binder or pitch and the mixture, it has become possible to gain the same

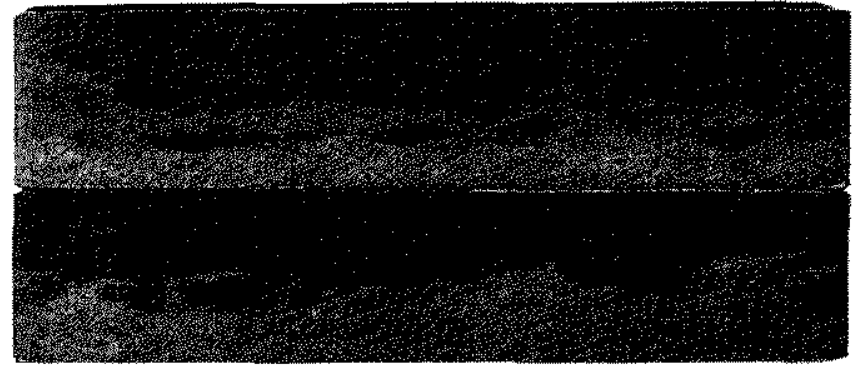

FIG. 6.

shrinkage in the two widely different materials, a hard brush body and a body largely composed of graphite. A sort of laminated brush is thereby prom duced and if there were service demands for such laminated brushes they could be produced.

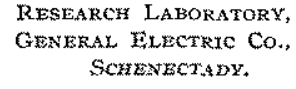

\section{THE RELATION OF THE REFRACTIVE INDEX OF SODA LIME GLASSES TO THEIR CHEMICAL COMPOSITION.}

By EDWIN WARD TILLOTSON, JR.

Through the researches* of Abbe, Schott, Winkelmann and others, it has been shown that many of the physical constants of glasses may be roughly calculated, with the aid of empirical factors, from their chemical composition. In all of those calculations it was assumed that the constant of the glass was the additive sum of the empirically determined constants of the oxides present, and it was shown that these empirical constants, since they must contain an element characteristic of the manner in which the oxide is combined in the glass, may be very different from the constant of the corresponding pure oxide. No data was presented for calculating the refractive index, although, both from the scientific and industrial standpoints, it is one of the most valuable of constants.

Many expressions for the relation of the refractive index to the density of a substance have been developed, but only two have theoretical significance. The first of these, $\frac{N-r}{d}=\mathrm{K}$, was proposed by Gladstone and Dale and the second, $\frac{N^{2}-1}{N^{2}+2} \times \frac{x}{d}=K$, was simultaneously and independently developed by Lorenz $z^{3}$ and Lorentz.4 In both of these expressions $\mathrm{K}$, the specific refractive power, is a constant which is supposedly independent of the temperature, and which is defined by the chemical composition and constitution of the substance. Many exceptions to this rule occur, however, and the expression of Gladstone and Dale fails completely when the vari-

\footnotetext{
" "Jena Glass and its Scientific and Industrial Application" Hovestadt.

2 Phil. Trans., 337, 186.3 .

${ }^{3}$ Wicd. Ann., 11, 70 (1880).

4 lbid., 9, 641 (1880).
} 
ation of temperature is sufficient to produce a change of state in the substance. Both expressions hold fairly well, however, for liquids and solutions. In a solution or a homogeneous mixture of liquids, which do not react to form a compound, the specific refractive power is an additive function of the respective refractivities of the compounds present and may therefore be calculated as follows:

$$
\mathrm{K}=\frac{p_{1} \mathrm{~K}_{1}}{\mathrm{I} 00}+\frac{p_{2} \mathrm{~K}_{2}}{\mathrm{I} 00}+\frac{p_{3} \mathrm{~K}_{3}}{\mathrm{I} 00}+\ldots \ldots
$$

in which $p_{1}, p_{2}, p_{3}$, etc, are the percentages in which the several compounds are present, and $\mathrm{K}_{1}, \mathrm{~K}_{2}, \mathrm{~K}_{3}$, etc., are their respective specific refractivities.

Very few attempts have been made to apply this relation to glasses or to pure silicates. Larsen ${ }^{\mathbf{1}}$ has shown by some very accurate measurements on carefully prepared silicates that the specific refractive power is additive within limits of error in case of mixtures of calcium and magnesium metasilicates, and of albite and anorthite. both in the vitreous and the crystalline form. A marked difference, however, occurs in the values of the specific, refractive power for the vitreous and crystalline compounds of like composition.

This paper is an account of an investigation on the refractive index and the specific refractive power of some soda lime glasses for the purpose of obtaining data, whereby these refractive indices might be calculated from their composition with a fair degree of accuracy. The glasses were prepared from pure sodium carbonate, pure calcium carbonate and a high grade of glass sand which analyzed $98.5 \% \quad \mathrm{SiO}_{2}$, the remainder being chiefly aluminum oxide and moisture. The ingredients were carefully weighed out, well mixed and finally fused in clay crucibles in an oxidizing atmosphere of a gas furnace. When the glass was "plain" it was poured out on cold iron plates and, after annealing, was broken into small fragments. The refractive index for white light was measured with the aid of an Abbe refractometer using selected fragments of the glass which presented a smooth, flat surface of the original plate. With a little care in selecting plane fragments of the glass, the values of the refractive index for successive plates usually agreed to within two or three units in the third decimal place, and the average of a number of readings was finally taken.

It is evident that, in the procedure as set forth, there are several chances for error. The glass could not be obtained free from striae in one or even two fusions when clay crucibles were employed, owing to the solvent action of the glass on the crucible; and the melts were stirred very little, therefore, in order that as few impurities as possible should be introduced. It is improbable that the lack of homogeneity, as shown by striae, introduced a very marked error, since the refractive indices of successive preparations ${ }^{2}$ of the same glass, measured on carefully ground and polished plates, agreed to within two units in the third decimal place. That this is within the limit of error

1 Am. J. Sci., 28, 263 (1909).

2 Unpublished data. for glass prepared in clay crucibles is shown by the fact that, even in the manufacture of optical glass, which must possess homogeneity to the highest degree, it is customary to find a difference in a large plate amounting to several units in the fourth decimal place and not uncommon to find a difference of one unit in the third decimal place, and also, by the fact that manufacturers cannot vouch ${ }^{2}$ for the refractive index of a crown glass to within two units, or for a flint glass to within six or eight units in the third decimal place. The errors arising from preparation and from optical measurements are therefore probably small in comparison to those introduced into the values of the specific refractivities by the use of the calculated densities. It has been shown in a previous paper ${ }^{3}$ that the densities of many glasses may be calculated with a moderate degree of accuracy, from the chemical composition. The average error in these computed densities was about one per cent., but occasionally amounted to two per cent. An error of one per cent. in the density produces an error in the refractive index, when it is about $r .5$, of five units in the third decimal place, and about one unit in the second place when it is I.6. In the specific refractivity (Lorenz and Lorentz), one per cent. error in the density introduces an error of from $0.0005^{-}$ $0.00 \mathrm{ro}$. ' It is also possible that an additional error was introduced in the composition of the glasses. No analyses of the glasses were made, but the composition was assumed to correspond to that of the "batch." This error is doubtless small in comparison with other errors since Kultascheff 4 has shown that, although the loss on heating pure sodium metasilicate may amount to $4 \%$, as the percentage of calcium silicate increases the loss rapidly decreases and becomes negligible; and Day and Allens apparently did not observe any noticeable volatilization in the synthesis of feldspar.

The results which were obtained are given in Table I. The first four columns of this table show the composition of the glasses, which correspond to mixtures ranging from $\mathrm{Na}_{2} \mathrm{O} .3 \mathrm{SiO}_{2}$ to $\mathrm{CaO} . \mathrm{SiO}_{2}$. In the fifth column are given the densities as calculated ${ }^{6}$ from the composition; in the sixth, the observed refractive index for white light; and in the seventh, the values of $\mathrm{K}$ which were calculated from Gladstone and Dale's formula.

When these values for $K$ are plotted in a system, in which the ordinates represent the composition and the abscissas the specific refractivities, as shown in Fig. I, it becomes evident that they form two straight lines which intersect at a point corresponding to a glass of the composition $2 \mathrm{Na}_{2} \mathrm{O} .3 \mathrm{CaO} .9 \mathrm{SiO}_{2}$. This break in the curve, therefore, indicates the existence of a compound at this point. It is especially significant since both Kultascheff 7 and Wallace ${ }^{8}$ have

\footnotetext{
${ }^{1} Z$ scholke, $Z$ eit. für Instrumentenk, 29, 286.

2 Hovestadt, loc. cit, p. 18.

3 Tillotson, This Journal, 3, 897 (1911)

4 $Z$. anorg. chem., 35, 187 (1903).

5 "The Isomorphism and Thermal Properties of the Feldspars."

- Hovestadt, loc, cit. Tillotson, loc, cit.

7 . anorg. Chem., 35, 187 (1903).

8 Ibid., 63, 1 (1909).
} 


$\begin{array}{ccc}\mathrm{CaSiO}_{3} \text { mol. } & \mathrm{SiO}_{2} . & \mathrm{CaO} . \\ \mathrm{Per} \text { cent. } & \text { Per cent. } & \text { Per cent. } \\ 00 & 74.45 & 0.00 \\ 10 & 73.60 & 2.50 \\ 20 & 72.32 & 5.18 \\ 30 & 70.85 & 8.25 \\ 40 & 69.30 & 11.70 \\ 50 & 67.40 & 15.60 \\ 50 & 67.40 & 15.60 \\ 60 & 65.20 & 20.20 \\ 70 & 62.75 & 25.35 \\ 80 & 59.60 & 31.80 \\ 80 & 59.60 & 31.80 \\ 100 & 51.85 & 48.15 \\ -N_{m a} \text {-Larsen. loc cit. } & \end{array}$

\begin{tabular}{cl}
$\begin{array}{c}\mathrm{Na} \mathrm{a}_{2} \mathrm{O} . \\
\text { Per cent. }\end{array}$ & \multicolumn{1}{c}{$\mathrm{D}$} \\
calc. \\
25.55 & 2.37 \\
23.90 & 2.395 \\
22.50 & 2.42 \\
20.90 & 2.45 \\
19.00 & 2.48 \\
17.00 & 2.52 \\
17.00 & 2.52 \\
14.60 & 2.57 \\
11.90 & 2.63 \\
8.60 & 2.705 \\
8.60 & 2.705 \\
$\cdots$ & 2.92
\end{tabular}

observed that in mixtures of sodium and calcium metasilicates a maximum melting point is reached at the composition $2 \mathrm{Na}_{2} \mathrm{O} .{ }_{3} \mathrm{CaO} .5 \mathrm{SiO}_{2}$. In column 8

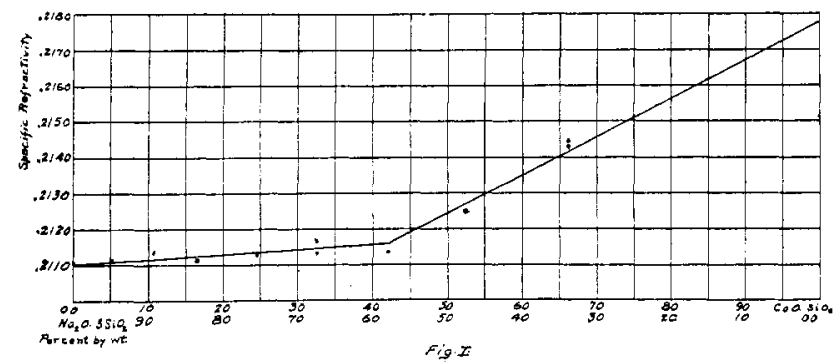

(Table I) are given the specific refractivities, as indicated by the two straight lines in Fig. I; column 9, the refractive index computed from columns 5 and 8 ; and column Io, the difference between the calculated and observed values of the refractive index.

In Table II are shown similar data for these same glasses, calculated from the formula of Lorentz and Lorenz, and in Fig. 2 the graphic relation of the specific refractivities to the composition. It will be noticed that the same break is observed in the refractive curve as shown by the full lines in Fig. II.

\section{TABLE II.}

\begin{tabular}{|c|c|c|c|c|c|c|}
\hline \multicolumn{7}{|c|}{$\begin{array}{c}\mathrm{CaSiO}_{3} \\
\text { mol. }\end{array}$} \\
\hline $\begin{array}{l}\text { Per } \\
\text { cent. }\end{array}$ & $\begin{array}{c}\text { D } \\
\text { calc. }\end{array}$ & $\begin{array}{c}x \\
\text { obs. }\end{array}$ & $\begin{array}{l}\mathrm{K}^{\prime} \\
\text { obs. }\end{array}$ & $\begin{array}{c}\mathrm{K}^{\prime} \\
\text { calc. }\end{array}$ & $\begin{array}{c}N \\
\text { calc. }\end{array}$ & $\begin{array}{c}\mathrm{N} \\
\text { calc.-obs. }\end{array}$ \\
\hline 00 & 2.37 & 1.500 & 0.1241 & 0.12422 & 1.5006 & +0.0006 \\
\hline 10 & 2.395 & 1.506 & 0.12406 & 0.12389 & 1.5054 & -0.0006 \\
\hline 20 & 2.42 & 1.5115 & 0.1239 & 0.12349 & 1.5110 & -0.0005 \\
\hline 30 & 2.45 & 1.5172 & 0.12351 & 0.12361 & 1.5176 & +0.0004 \\
\hline 40 & 2.48 & 1.524 & 0.12338 & 0.12346 & 1.5244 & +0.0004 \\
\hline 50 & 2.52 & 1. 5334 & 0.12329 & 0.12323 & 1.5333 & -0.0001 \\
\hline 50 & 2.52 & 1.530 & 0.12260 & 0.12323 & 1.5333 & +0.0033 \\
\hline 60 & 2.57 & 1. 5432 & 0.12272 & 0.12300 & 1.5450 & +0.0018 \\
\hline 70 & 2.63 & 1.559 & 0.12277 & 0.12270 & 1.5586 & -0.0004 \\
\hline 80 & 2.705 & 1.580 & 0.12305 & 0.12236 & 1.5761 & -0.0039 \\
\hline 80 & 2.705 & 1.5796 & 0.12298 & 0.12236 & 1.5761 & -0.0035 \\
\hline 100 & 2.92 & $1.628^{1}$ & 0.12155 & 0.12150 & 1.6276 & -0.0004 \\
\hline & $43^{2}$ & 1.5096 & 0.12300 & 0.12291 & I. 5093 & -0.0003 \\
\hline
\end{tabular}

This break is, however, less marked than in the case shown in Fig. I, and all of the specific refractivities may, for convenience, be considered to lie upon a single straight line indicated by the dotted line in the figure. This behavior of the $\mathrm{N}^{2}$ formula, that of minimizing the effects of compounds on the specific refractivity, makes it possible to calculate the specific refractivities directly from the percentage composi-

1 Nna Larsen, loc cit.

$2 \mathrm{SiO}_{2}, 77.7 \% ; \mathrm{CaO}, 8.5 \% ; \mathrm{Na} \mathrm{O}_{2}, 13.8 \%$
TABLE I.

$\begin{array}{clllr}\begin{array}{c}\mathrm{N} \\ \text { obs. }\end{array} & \begin{array}{c}\mathrm{K} \\ \text { obs. }\end{array} & \begin{array}{c}\mathrm{K} \\ \text { calc. }\end{array} & \begin{array}{c}\mathrm{N} \\ \text { calc. }\end{array} & \begin{array}{r}\mathrm{N} \\ \text { calc. -obs. }\end{array} \\ 1.5000 & 0.2110 & 0.2110 & 1.5000 & 0.0000 \\ 1.5060 & 0.21127 & 0.2111 & 1.5055 & -0.0005 \\ 1.5115 & 0.21137 & 0.21118 & 1.5111 & -0.0004 \\ 1.5172 & 0.21110 & 0.21125 & 1.5175 & +0.0003 \\ 1.5240 & 0.21129 & 0.21135 & 1.52410 & +0.0001 \\ 1.5334 & 0.21166 & 0.2115 & 1.5330 & -0.0004 \\ 1.5300 & 0.21032 & 0.2115 & 1.5330 & +0.0030 \\ 1.5432 & 0.21137 & 0.2116 & 1.5438 & +0.0006 \\ 1.5590 & 0.21254 & 0.2127 & 1.5594 & +0.0004 \\ 1.5800 & 0.21442 & 0.2142 & 1.5794 & -0.0006 \\ 1.5796 & 0.21436 & 0.2142 & 1.5794 & -0.0002 \\ 1.6281 & 0.21517 & 0.2178 & 1.6307 & +0.0027\end{array}$

tion of the glass. Since the specific refractivity is, within the limits of error, linear, it may be computed by means of the following equation:

$$
K=\frac{P_{1} K_{1}}{I 00}+\frac{P_{2} K_{2}}{I 00}+\frac{P_{8} K_{8}}{I 00} \text {, etc. }
$$

in which $P_{1}, P_{2}, P_{3}$, etc., are the percentages of the oxides, and $K_{1}, K_{2}, K_{3}$. etc., are the empirically determined specific refractivities of the oxides. For soda lime glasses these are as follows:

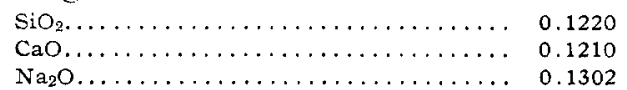

Columns 5 and 6 of Table II show the specific refractivities and refractive indices as calculated by the aid of these factors and column 7 the difference between the calculated and observed values of the refractive index. Not only are the computed values for the glasses given above sufficiently accurate for many kinds of work, but the last glass in Table II shows that the refractive index of glasses richer in silica, may also be calculated with equal accuracy.

Although, in employing this method for estimating the refractive index, no consideration is taken of the compounds which may be formed, yet it is theoretically correct up to the point where the compound is found, and is applicable to the majority of soda lime glasses; for these rarely contain as large a proportion

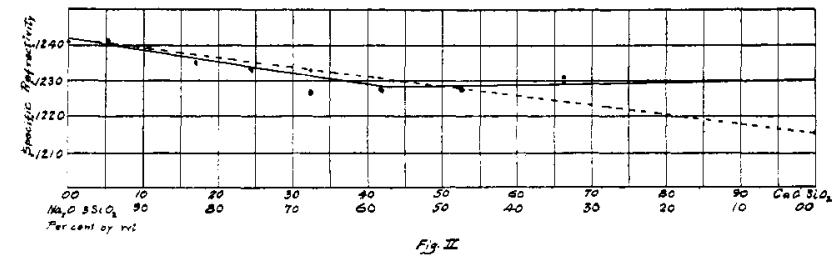

of lime as the ratio ${ }_{2} \mathrm{Na}_{2} \mathrm{O} \cdot{ }_{3} \mathrm{CaO} \cdot x \mathrm{SIO}_{2}$ calls for, and they therefore lie to the left (Figs. I and II). of the break in the specific refractivity curve, and in the region for which the factors, given above, furnish the most satisfactory agreement. It must be remembered, however, that the factors employed represent not the true specific refractivity of the pure oxide, but the true refractivity modified by the nature of the silicate which is formed and also by the inexact values of the density which is employed in the calculations. This is well illustrated in Table III, in which are shown therefractive indices of several oxides, together with the density observed, the density em- 
ployed in the computations and the specific refractivities calculated from them, together with the factors given above.

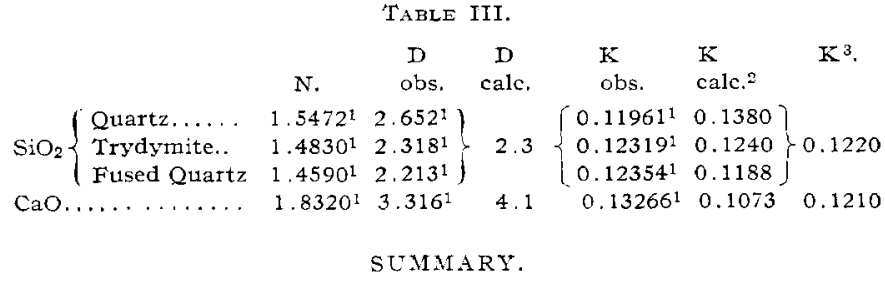

I. A series of soda lime glasses have been made and their refractive indices measured.

2. The existence of a double silicate of the type $2 \mathrm{Na}_{2} \mathrm{O} .3 \mathrm{CaO} . x \mathrm{SiO}_{2}$, which is doubtless the double metasilicate, described by Kultascheff and Wallace, has been made evident.

3. The specific refractivities of these glasses, computed with the aid of the calculated densities, are additive from pure sodium silicate up to the composition in which the molecular proportion of soda to lime is $2: 3$.

4. Factors have been derived by means of which the specific refractivity of soda lime glasses may be calculated. These are for the formula of Lorentz and Lorenz: $\mathrm{SiO}_{2}, \mathrm{I} 220 ; \mathrm{CaO}$, I210; $\mathrm{Na}_{2} \mathrm{O}, 0.1302$.

LNIVERSITY OF KAXSAS,

I.AWRENCE, KANSAS.

\section{A NEW METHOD FOR THE DETERMINATION OF VANADIUM.}

BY D. J. DEMOREST.

Received September 25, 1911

The following method for the determination of vanadium in steel depends upon the selective oxidation of ferrous sulfate in the presence of vanadyl sulfate by means of manganese dioxide. The vanadyl sulfate is then titrated by adding an excess of permanganate, the excess permanganate being titrated by sodium arsenite.

This differential oxidizing action apparently contradicts the results of $\mathrm{J}$. R. Cain, ${ }^{4}$ who found that both iron and vanadium are oxidized, but the reasons for this discrepancy are shown in the note which follows on page 256 .

The manganese dioxide should be sufficiently fine to pass through a $200-$ mesh sieve, and yet should settle in a beaker of water in 30 seconds.

The process in detail is as follows: In a $500 \mathrm{cc}$. flask a two-gram sample of the steel or iron is dissolved in a mixture of $30 \mathrm{cc}$. of water and I 2 cc. concentrated $\mathrm{H}_{2} \mathrm{SO}_{4}$ with application of heat. Then one cc. of $\mathrm{HNO}_{3}$ (sp. gr. I.42) is added cautiously to oxidize the iron and the solution is boiled for a few minutes to remove the nitrous fumes. Then the solution is diluted with $30 \mathrm{cc}$. of water and a strong solution of $\mathrm{KMnO}_{4}$ is added to completely oxidize all carbon, etc., and the solution is boiled. If the per-

1 Larsen, loc. cit.

2 Using Lorentz and Lorenz formula and "D cale."

3 Factors used in computing specific refractivities.

4 THIS JOURnal, 3, 476 (1911) manganate or the resulting $\mathrm{MnO}_{2}$ should disappear, not enough permanganate has been used, and more should be added. Now ferrous sulfate is added to reduce the $\mathrm{MnO}_{2}, \mathrm{HMnO}_{4}, \mathrm{H}_{2} \mathrm{CrO}_{4}$, and $\mathrm{H}_{3} \mathrm{VO}_{4}$, etc., and the solution is again boiled to remove any possible nitrous fumes. Then pure distilled water is added to make the volume about $250 \mathrm{cc}$., $N /$ ro $\mathrm{KMnO}_{4}$ added until the solution is pink, and the solution cooled to tap water temperature. Ferrous sulfate solution is added until all reducible compounds including chromic and vanadic acids are reduced. Only enough ferrous sulfate should be added to be certain that there is a decided excess present. A solution, one cc. of which equals about $0.0 \mathrm{I}$ gram of iron, is the one used. Now about one gram of C. P. $\mathrm{MnO}_{2}$ is added and the solution shaken vigorously. After two minutes a drop is tested with ferricyanide on a white plate to see if the iron is completely oxidized. It generally takes from four to six minutes. At the end of each minute the solution is tested for ferrous iron until none is present and the shaking is continued for about one-half minute longer. It should be noted that a bluish color will always be obtained in the presence of vanadyl sulfate after the test drop has stood for a few seconds. The end should be taken when the test does not show blue immediately. The blue color which forms after a few seconds, even when there is no ferrous iron present, is due to the reduction of ferri- to ferrocyanide by the vanadyl sulfate. One can become familiar with this end by adding a drop of ferric sulfate containing vanadyl sulfate to a drop of ferricyanide on a white plate.

The $\mathrm{MnO}_{2}$ oxidizes the ferrous sulfate to ferric sulfate, but does not oxidize the vanadyl sulfate $\left[\mathrm{V}_{2} \mathrm{O}_{2}\left(\mathrm{SO}_{4}\right)_{2}\right]$. Then the $\mathrm{MnO}_{2}$ is filtered off on an asbestos mat, using suction. From a burette a standard solution of $\mathrm{KMnO}_{4}$ is added until a pink tinge is present in the solution, and one cc. more is added, and after one minute the excess permanganate is titrated with $\mathrm{Na}_{3} \mathrm{AsO}_{3}$ solution. The end point is very sharp. If at this point the operator is not satisfied with this titration, the excess arsenite may be oxidized with $\mathrm{KMnO}_{4}$, ferrous sulfate again added, then oxidized with $\mathrm{MnO}_{2}$ as before, and the titration repeated, thus giving a check on the titration. A blank determination must be run on a vanadium-free steel, and the result deducted. The blank generally amounts to about $0.00075 \mathrm{gram} \mathrm{V}$. The time required is about one-half hour and the results are very satisfactory. In fact the accuracy is about that of a phosphorus determination.

The vanadium steel standard furnished by the Bureau of Standards was analyzed by the above method. The result of the Bureau chemists is 0.0143 per cent. $\mathrm{V}$ and the average of the cooperating chemists is 0.15 per cent. V. The writer obtains the following results, the average being 0 . I 43 per cent.:

$\begin{array}{ll}0.140 & 0.138 \\ 0.147 & 0.147 \\ 0.143 & 0.143\end{array}$

To further test the method, two-gram samples of 